\title{
XXXVI. On binaural audition
}

\section{Silvanus P. Thompson B.Sc. B.A.}

To cite this article: Silvanus P. Thompson B.Sc. B.A. (1877) XXXVI. On binaural audition, Philosophical Magazine Series 5, 4:25, 274-276, DOI: 10.1080/14786447708639338

To link to this article: http://dx.doi.org/10.1080/14786447708639338

$$
\text { 曲 Published online: } 13 \text { May } 2009 .
$$

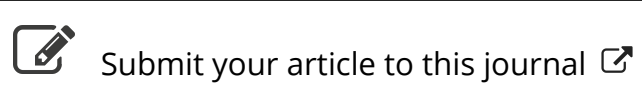

Шll Article views: 11

Q View related articles $\sqsubset$ 


\section{[ 274$]$}

XXXVI. On Binaural Audition. By Silvanus P. Thompsov, B.Sc., B.A., Lecturer in Experimental Physics, University College, Bristol*.

1. DURING the course of a series of experiments made a few months ago I had occasion to listen to a tone of slightly fluctuating pitch, the sound of which was led to one ear by a caoutchouc tube. Desiring to measure the pitch of the tone, it occurred to me to try to obtain interference-beats with a fork of very nearly the same pitch. Under the circumstances this could only be accomplished by holding the vibrating standard fork to the other ear. On doing this I was somewhat surprised to observe that the "beats" were heard with remarkable distinctness. Up to this time I was not aware of any experiments on the binaural estimation of beats, nor even that they could be so heard. Shortly afterwards I learned from Dr. W. H. Stone that he has been in the habit of using both ears, with a tuning-fork applied to each, in counting beats, and that he finds no difference between the result of this method and that of listening to both forks with one ear.

2. When two forks producing "bèats" are thus applied, one to each ear, there is a possibility of the vibrations of the one fork being conveyed to the other ear exteriorly through the air. To eliminate as nearly as possible this chance I took two $\mathrm{UT}_{3}\left(c^{i}=256\right)$ forks, by Ducretet of Paris, and loaded one with wax to give about 2.5 beats per second when sounded with the other. The forks were unscrewed from their resonant boxes; an india-rubber tube was inserted into an aperture in the wall of each of the resonant boxes corresponding to the forks; and the two tubes were led to the two ears of the observer, and plugged round with cotton-wool. For the sake of greater precision, the tubes were led away from the apartment into two others, in each of which an assistant struck one of the forks and held it in front of the mou'h of the resonant box. The "beats" were most distinctly heard, and seemed to be taking place within the cerebellum. When the forks vibrated so slightly as to be singly all but inaudible, the beats of the two were most distinctly heard.

3 . When the beats were augmented in number per second by additional loading, they were still very distinet to binaural audition, and unusually barsh. On listening attentively for a combinational (difference) tone, none was observed. Two

* Communicated by the Author, haring been read before the British Association, Section A, August 16, 1877. 
forks, $\mathrm{UT}_{3}$ and $\mathrm{MI}_{3}$, which when struck or bowed together give a well-marked combinational tone, gave none when their sounds were separately led to the two ears. The same was the case with $\mathrm{UT}_{3}$ and $\mathrm{SOL}_{3}$. The effect was not entirely agreeable, being peculiarly harsh, yet unlike any ordinary discord. When $\mathrm{MI}_{3}$ and $\mathrm{SOL}_{3}$ were thus employed together, giving an interval of a minor third, no combinational tone was produced, but the effect was disagreeable and grating in the extreme-a most unpleasant jarring sensation being excited, apparently in the region of the top of the cerebellum. Several observers concurred in the absence of any combinational tone, and in the unpleasantness of the resultant sensation.

4. The next experiment was an attempt to ascertain the effect of bringing to the two ears waves of equal pitch and intensity, but differing in phase. A series of more elaborate experiments on this point is still in course of completion; but before these were begun the following simple experiment was tried. One of $\mathrm{my}^{\mathrm{t}}$ two $\mathrm{UT}_{3}$ forks was loaded until it gave two beats per second with the other. When they were sounded together, there was obviously produced a rapid succession of all possible differences of phase. A slower succession of interferences was afterwards employed. When the two forks were presented separately (and simultaneously) to the two ears, and also when their tones were independently led to the cars by tubes as described above, it was still possible to recognize the fluctuations of tone. There was, however, ro very decided weakening of the intensity of the sound comparable to the "silences" ordinarily observed between the "beats," the two tones seeming to be going on, but with a difference hardly definable in presise terms. When complete difference of phase was momentarily attained, there seemed to be a slight increase in the intensity of the sound, and the octave note (which, it will be remembered, is not amongst the upper partials of the fork) was faintly heard *. There was, however, no means of demonstrating the existence of such a tone, and the statement rests merely upon the evidence of the senses.

5. It is not easy to explain why interference-beats should thus occur in the simultaneous individual action of the two ears, while combinational tones (difference-tones) are inaudible. There is in the case of the auditory nerves, or

* It is of some importance to observe that in this experiment the forks were held by assistants, and detached from their resonant boxes; as described in No. 2. 
portio mollis, no decussation like that of the optic nerves; the former do not intersect after leaving the fourth ventricle, in which they have their common origin, and from which they diverge right and left. There is in health a possible communication between the ears across the pharynx, through the Eustachian tubes. Moreover the bone of the skull itself is capable of conveying sonorous tremors, which might account for both ears hearing a sound entering by one only. In either of these latter cases, however, there would be no reason why combinational tones should not be equally andible in binaural as in monaural audition; so that we are driven to the hypothesis that any means of comparison which may exist in the nerve systems of the ears exists deep-seated in the actual structure of the brain. This may be the reason why dissonances are in binaural audition so excessively disagreeable, and why even ordinary consonant intervals become harsh. They evoke a discontinuous sensation when there is no opportunity of their blending previously to acting upon the sensitive mechanism of the nerve-structures. The discontinuity of the sensation produces an intensity of effect exceeding that of a continuous one. Hence sounds all but inaudible themselves may yield, as noted in No. 2, very wellmarked beats, enabling the ear thus to detect the most delicate differences of tone. Thus, for example, I have, in a still room, huing up a fork with its resonant box, and, after exciting its vibrations with a bow, have made it swing like a pendulum at the end of a string. On retiring to the further end of the room, and listening to its tones with a resonator in the ear, I have, by holding to the other ear a fork vibrating accurately in unison with the first, been able to pronounce by the audible fluctuations of tone whether the swinging fork were advancing or retreating-that is to say, whether the motion of translation at any given moment were in the same direction as, or in an opposite direction to, the propagation of the sonorous waves.

XXXVII. On the Magnetic Behaviour of Chemical Compounds. By Professor G. Wiedemann.

[Concluded from p. 173.]

11. MAGNETLSMS of the Oxides of the Magnetic Metals. -The oxides, having been heated to redness, investigated directly in the flat flasklet, show in general a much feebler magnetism than the corresponding salts or hydrates. 